\title{
REVIEW
}

\section{Strategies for post-conflict development of the Health Systems in Somalia: lessons from selected countries}

\author{
Maye Omar \\ Associate Professor in International Health System, Nuffield Centre for International Health and Development, University of \\ Leeds, United Kingdom
}

\begin{abstract}
Until the beginning of 1991, Somalia had a reasonable health care system with a good number of major hospitals in Mogadishu and Hargeisa, some regional hospitals, district hospitals, clinics, mother and child health centres $(\mathrm{MCH})$ and out-patient dispensaries. However, the conflict resulting from civil war has destroyed the public health care system which existed in the country.

Somalia was not alone in having conflicts. The total number of conflicts in the world in 2019 was 54, many of them have now entered post-conflict phases, where open warfare has come to an end. There is growing evidence that conflict has a devastating impact on health systems and the health status of the population.

In Somalia, the post conflict phase provides a unique window of opportunity for health sector development and reform. At this juncture, health systems in Somalia face the double burden of a flawed pre-conflict health system, characterised by deficiencies and inequities, and the long-term impact of conflict on the health status of the population and its resultant strain on the health system.

This review article analyses the framework for rehabilitation of health systems in postconflict countries. Such knowledge can be applied in the rehabilitation and development of health systems in Somalia along the lines of the World Health Organization's health system building blocks.

The impact of conflict on the health status of the population as well as the health system can be catastrophic and be felt for years after the State has entered the postconflict phase, but also provides an opportunity for reforms of the affected State's health sector.
\end{abstract}

\section{ARTICLE HISTORY}

Received 18 November 2020

Accepted 9 June 2021

\section{RESPONSIBLE EDITOR}

Lars L Gustafsson

\section{KEYWORDS}

Conflict countries, framework, health system, post-conflict rehabilitation, Sierra Leone, Somalia, Uganda.

\section{Background}

Until the end of 1990 and prior to the collapse of its state in early 1991, Somalia had a good number of general hospitals (though they were mainly concentrated in big urban areas, like Mogadishu), some regional hospitals, clinics, mother and child health $(\mathrm{MCH})$ centres, outpatient dispensaries and a public health system [1]. Starting from the early 1970s, for instance, the number of physicians increased significantly, the greater proportion of them being native Somalis. On the other hand, in the 1970s and 1980s, great efforts were made to increase the number and quality of other health professionals by establishing health educational programmes in the form of medical, nursing and other health professional training institutes $[2,3]$.
Prolonged civil war and armed conflict led to the destruction of health infrastructure, resulting in poor access to essential health services, exposing an already vulnerable population to high disease burden and malnutrition. Although healthcare now has been largely concentrated in the private sector and international aid agencies, the end of the conflict has resulted in the Somali Federal Government alongside international and domestic partners beginning the process of rebuilding its national health system.

Armed conflict is defined as the "use of arms in order to promote the parties' general position in the conflict, resulting in death" " [4]. 
The two types of conflict can be defined as:

- Interstate: disputes between two different states.

- Intrastate: encompasses civil, ethnic, anti-colonial, territorial and governmental control struggles [4].

In 2019, there were 54 state-based conflicts recorded globally: two more than in 2018 and the same number as in 2016. This number is a record high since 1946. Thirtyfive countries experienced civil conflicts and worldwide around 50,000 died in battle-related deaths [5]

In countries affected by conflict and crisis, particularly those with protracted crises such as Somalia, the functioning of the health system is significantly impaired. Often it has deteriorated to the point where public health care is no longer widely available [6].

The 'post conflict' phase is described as the situation in which open warfare has come to an end [7]. There is no clear cut beginning to this phase and sometimes can only be defined retrospectively [8] .

There is growing evidence that conflict has a devastating impact on health systems and the health status of the population [9]. On the other hand, the post conflict phase provides a unique window of opportunity for health sector reform. At this juncture, health systems of these countries, including Somalia face the double burden of a flawed pre-conflict health system, characterised by deficiencies and inequities, and the long-term impact of conflict on the health status of the population and its resultant strain on the health system $[8,10]$.

There is increasing literature on how to construct effective and sustainable health systems in post conflict states, which will be reviewed in this paper. The strengths and weaknesses of the strategies will be analysed and used to identify any gaps in the literature and draw lessons that can be applied in rebuilding, reforming and strengthening the health system in Somalia.

\section{Methodology}

\section{Theoretical framework}

The theoretical framework of this review article was based on the World Health Organization's (WHO) building blocks required for an effective health system [11] The effects of conflict on the health status of the population and health system, as well as pre-existing deficiencies, were explored in order to gain an insight into the challenges faced in rehabilitating the health system.

The World Health Organization's health systems framework highlights several critical factors when it comes to rebuilding health systems in post conflict settings. The framework used in this review focuses on six building blocks - service delivery, health workforce, health information systems, access to essential medicines, financing and leadership/governance; as these are key to realising more equitable and sustained improvements across health services and health outcomes [12]. The framework is therefore used to analyse the challenges and successes of rebuilding these individual blocks of the health system in Somalia's post conflict environment.

\section{Search strategy}

Published material regarding conflict and post-conflict situations was searched for using databases such as the 'conflict barometer 2018' [13] in order to gain a context of the number of people affected by war/conflict and its impact on the health system.

The search strategy encompassed the use of various databases such as Global health, PubMed, Popline and Medline. Database advanced search tools 'and' and 'or' were used in order to cover all the combinations and permutations of the potential titles that could be searched. Figure 1 below shows the list of terms and combinations in which they were used in order to find the literature.

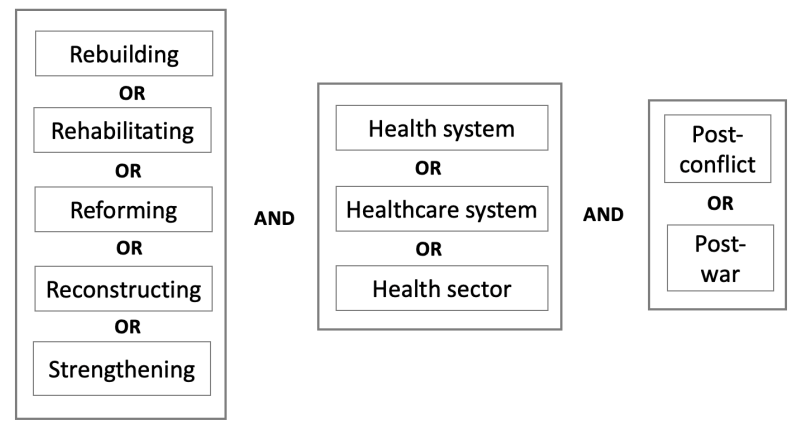

Figure 1: List of terms and combinations used for literature search

\section{Inclusion/Exclusion Criteria}

The chosen databases yielded 312 results, of which 120 were removed because of duplication. The Titles of the remaining records were then reviewed and removed from the search results if none of the key words were present in the title, or it was deemed inappropriate for the review in question. The abstracts of the remaining 87 records were read and records were removed if they fell into a number of unsuitable criteria. A further manual de-duplication concluded in 58 papers being read in full, which then became the base in this review.

Contemporary literature was preferably used, but older papers were not discounted as they often reviewed conflicts that had occurred earlier in history providing important findings regarding strategies that had been employed.

When researching the individual building blocks, references from existing papers were used to broaden the sources, and more specific searches were employed.

\section{Key findings from the review}

\section{Effects of conflict on the health status of the population}

Armed conflicts can impact a population in direct and indirect ways. The direct impacts of war are those that have an immediate effect on the current health status of the population - this includes mortality, morbidity, stress and the destruction of health facilities. The population is 
at risk of violence and torture, leading to long term mental health conditions as well as post-traumatic stress.

Damage to health facilities and looting reduces the availability of care to the population in need.

The indirect effects are those that are influenced by economic, political and social transitions that occur during conflicts. An increase in sexual violence can lead to the spread of HIV and other sexually transmitted infections [14,15]. Social issues, such as drug abuse, alcoholism, and domestic violence may increase during and after the conflict [16].

The displacement of the population during war, and the lack of water, hygiene and sanitation can increase the subsequent risk of communicable diseases such as measles, cholera, TB and malaria $[17,18]$.

The impacts of war can affect the population for many years following the conflict. A study by Ghobarah et al found that the burden of morbidity and mortality in 1999, as a result of conflicts occurring between 1991 and 1997, was nearly the same as the mortality and morbidity occurring during an armed conflict in 1999 [19]. Sufferers of chronic disease are also impacted, as the disruption to public services makes it harder for them to get medication and prevent the worsening of their condition [20].

There are challenges to obtain exact and accurate record in regard to changes of diseases burden in the country during a conflict due to inadequate or absent data systems, social breakdown, forced migration, reporting biases, and the fog of war. [21]. Among civilians, conflict promotes factors that lead to increased incidence of infectious diseases, including mass movement of populations, overcrowding, lack of access to clean water, poor sanitation, lack of shelter, and poor nutritional status [22].

Basically, war leads to epidemics because of poor sanitation and access to clean water, which leads to epidemics of cholera or tuberculosis. Conflicts can equally have devastating effects and can lead to mental health problems in people who are targeted and in others. Problems include post-traumatic stress disorder, anxiety, depression, substance misuse, and (rarely) precipitation of psychosis [23].

Damage to agriculture can also prove to be an indirect problem, as it can lead to widespread famine making the population weaker at fighting illnesses, increasing pressure on the health system [24-26].

\section{Effects of conflict on the health system}

War can impact on public health systems both instantly and for years to come. As a by-product of war, and sometimes an intentional ploy, health infrastructure such as hospitals are attacked and damaged $[27,28]$. The loss of equipment, supplies and the means to procure them, can severely impede the everyday functioning of the health system. This coupled with the exodus of health 'actors' such as doctors and nurses trying to escape the conflict $[29,30]$ can leave a health system with a greater workload, but with fewer health care workers and a reduced capacity from which to offer services. During wartime, the health budget is usually cut and diverted to the military budget impinging on the ability of the health system to function [31].

Evidences from countries affected by conflict show that healthcare facilities are often substantially affected, causing destruction of medicines and equipment, shortages of medicines and skyrocketing prices [32]. As the result of conflict, access to medicines that is important to millions of people becomes a problem. As the result, people are unable to obtain basic treatment and medicines for chronic illnesses such as cardiovascular illness, hypertension, and diabetes, or medicines for recurrent outbreaks of diseases such as cholera and dengue fever, resulting in high mortality and morbidity rates [33].

The negative impact on public health initiatives such as vaccination programs can leave the population at increased risk of disease, with the greatest impact on infants and mothers $[18,31,34]$

\section{Identifying the deficiencies that need to be addressed in post conflict health systems}

Health systems in post-conflict countries are described as fragile $[9,35]$. On the other hand, Newbrander et al identified the following characteristics of a fragile health system [36]:

- Lack of access to Health Services for the majority of the population especially those that exist outside the main urban areas.

- Non-functioning or poor referral systems in place for the critically ill.

- Inadequate infrastructure, including health facilities, equipment stores, medicines and human resources., that is unable to deliver health services to the population.

- Poor capacity building systems, such as training programs for health and management staff.

- Poor management of the health system at a national level (coordination, oversight and monitoring).

This may be due to the new governance brought in post-conflict.

- Inequity in the availability of health services, especially towards the poor and those in rural areas.

- Absence of health information systems, needed for planning and surveillance of the health system.

- Poor management capacity, this includes budgeting, human resource management and accounting [37].

On the other hand, corruption, lack of transparency and misuse of resources are prevalent during and after conflicts situations [38]. Studies have shown that corruption may have long term consequencs within a state, impacting the extent to which populations have shortened life expectancy on the top of mortality as the result of conflict $[39,40]$. Corrupt activities in the health sector in particular can have repercussions in three areas 
as illustrated in Table 1 [41].

Table 1: Corruption and its effects to the health sector

\begin{tabular}{|l|l|}
\hline $\begin{array}{l}\text { Aspects of } \\
\text { corruption }\end{array}$ & Effects of corruption on the health sector \\
\hline $\begin{array}{l}\text { Health and the } \\
\text { health care }\end{array}$ & $\begin{array}{l}\text { Corrupt activities are likely to harm the health } \\
\text { system's ability to deliver effective, high-quality } \\
\text { care to the people. It is increasingly evident } \\
\text { that high levels of corruption impoverish } \\
\text { populations, increase inequality and cause } \\
\text { deterioration in health, especially among the } \\
\text { most vulnerable population groups. }\end{array}$ \\
\hline Business activity & $\begin{array}{l}\text { The presence of a substantial quasi-private } \\
\text { system operating corruptly within the public } \\
\text { sector can be detrimental to the development } \\
\text { of a strong private sector. It can often be more } \\
\text { profitable for private providers to leverage } \\
\text { public facilities, with their medical equipment } \\
\text { and patient supplies, than to set up their own } \\
\text { clinics and patient recruitment mechanisms. }\end{array}$ \\
\hline Macro-economy & $\begin{array}{l}\text { Corruption drastically hampers economic } \\
\text { growth and private sector investment. } \\
\text { Corruption in the healthcare sector has had } \\
\text { repercussions on the macroeconomy. }\end{array}$ \\
\hline
\end{tabular}

Although corruption can be found in all countries and settings, its effects are particularly devastating in low- and middle-income countries, especially during and after conflicts, because of the breakdown of state institutions and governance systems [42].

If unchecked, health system corruption represents a significant drain on domestic health resources and is a major obstacle to efforts to reform the health systems as part of the universal health coverage agenda [43].

Post-conflict health systems in Somalia needs to be built with new foundations, due to the pre-existing issues that have evolved over time. For example, Gaber et al traced the challenges in post-conflict in Ivory Coast from 1893 to 2013 [44]. They analysed how history shaped the evolution of the health system and used this insight to study the macro level political, social and economic determinants of health over time. They believed that the identification of historical problems could be used to increase the effectiveness of new health policies in postconflict countries. Examples of the problems identified included the colonial policies that contributed to the inequity in health development amongst the different tribal groups, depending on the strategic roles that were assigned to them during the French colonial rule (18931960) [44].

Following a conflict, the initial strategies to be prioritised are those that target communicable disease outbreaks or the other direct impacts of war on mortality rates. Although this is the most beneficial way on the use of resources in the short term, it is important to use this time to start planning for a transition to a longer-term solution of rebuilding and strengthening the national health system $[36,45]$.

\section{Discussion of Strategies to rebuild health systems in post conflict countries}

\section{Strengthening of health services}

When rebuilding health services in a post conflict situation, the government and aid agencies need to decide whether to build on existing infrastructure or have a complete overhaul and start from scratch $[10,46]$

Macrae et al looked at the rehabilitation of health services in post-conflict Uganda. The Ugandan government had decided to restore the health services of the pre-conflict era, and implement a widespread expansion of primary health care to the underserved areas. They chose this method so that they did not have to reform the financing and provision of secondary care and tertiary care [10].

Macrae et al found that the successes of this approach were that there was a physical rehabilitation of the infrastructure, increased immunisation coverage and a better supply of essential drugs. The process involved community participation, which fostered reconciliation amongst the community. The challenges faced were that due to the prioritisation of the vertical health programmes there was limited capacity building. Like in Somalia today, there was also a proliferation of projects rather than a central national strategic policy. The increase in health services offered also increased the recurrent costs that were unsustainable, leading to high levels of donor dependency [47].

Lee et al looked at the strengthening of the Liberian health services. In 2010 the Liberian health sector increased the amount of health facilities in the country so that each facility was serving 5,500 people down from 8000 in 2006 , with $80 \%$ of the facilities meeting the minimum standard for provision. But in doing so they had not properly planned the construction. They neglected to check the potential utilisation, population needs, access (geographical) and costs of the projects and went ahead with them. This resulted in large amounts of capacity and resources being funnelled into inefficient programs, with over $50 \%$ of government clinics either serving populations that were too small or too large [48].

There are other programs spearheaded by Somali diapora which aimed at development, reconstruction and capacity building could provide valuable lessons. These include; Migration for Development in Africa (MIDA) health Finland Somalia (FINNSOM), Transition Initiatives for Stabilization (TIS), Capacity Building for Somalia and Capacity injection program by International Organization for Migration (IOM) and World Bank. These programs, aim at tapping the diaspora skills gained from the countries of diaspora residence to their home country [49]. 


\section{Lessons for Somalia}

- The benefits of building on an existing health system are that it makes use of existing infrastructure. This can be used as a base for any deficiencies to be addressed, in this case the expansion of primary care.

- When building new infrastructure it is important to do a situation analysis to assess the needs and requirements before building new facilities, avoiding the issue of under-used and over-subscribed health services.

- Capacity building is important among local staff so that the transition from donor-dependant to a government-led system is smoother.

- To avoid funding gaps, the recurrent maintenance costs from the development of new facilities should be financially viable and not donor dependant. For example, the involvement of local and diaspora communities to participate in restoring, rehabilitating and developing the country's overall health system.

\section{Developing a functioning health workforce}

The loss of health cadre during conflict through casualties of war and mass exodus leaves many post-conflict health systems with a lack of capacity to deliver healthcare both at a clinical and management level. It is therefore important to set up institutions to train staff in the skills that are required in the post-conflict environment.

Huichol et al suggested the development of a framework in which priority was given to training and staffing underserved areas and primary health services. The services should be delivered by multi-skilled personnel with a good skills mix at each respective level, and training programs supplied in a cost-effective manner based on identification of needs [50]. Funding and technical support is also needed from external sources to develop these frameworks, but with an endgame of slowly weaning international assistance. This is important to enable sustainability and ownership by the government of the country .

In order to achieve sustainability and ownership, Snell et al using the experience of East Timor, suggested creating a model for meaningful collaboration between external agencies and their local counterparts, helping to develop long-term professional relationships. They also suggested the consideration of a cross sectional approach encompassing public, private, NGOs and religious organisations [51].

Fujita et al analysed a framework for human resources in health systems of post conflict and fragile states. Their main recommendations echoed those of Snell et al, however, they emphasised the importance of a situation analysis of human resource development, taking into account the socio-cultural background and the characteristics of the conflict. They also found that a lot of governments, as suggested by Snell et al, concentrated on developing training systems for staff, but neglected other important components such as a legal framework. Innovations in recruitment were also seen as an advantage, an example given was the contracting of local students in Cambodia and Afghanistan [52].

\section{Lessons for Somalia}

- The setting up of training programmes for staff in underserved regions and districts of the country should target inequity in human resources and service delivery.

- Services must be delivered by adequately trained personnel with a good skills mix.

- There is an initial need for collaboration between development partners with capacity building which will eventually transfer to a locally run system in the regions.

- Situation analysis of human resources must be taken into account, while considering innovative methods of staff recruitment at local level.

- Need to strengthen issues such as the legal and regulatory framework for human resources for health.

- Clearly define and coordinate human resources development components, on one hand, the management-employment-retention functions and on the other hand, the policy and planning, finances and legal functions.

\section{Implementing a health information system}

A study by Mutale et al looked at strategies to implement health information systems in five Sub-Saharan African countries. They described the main challenges as 'complex' and the roles of international donors implementing vertical programs. The complexity described the uneven development and distribution of health facilities and resources in urban and rural areas.

Issues regarding availability of electricity, computers, skilled operators and other forms of communication were a barrier in achieving an equitable system. Secondly the role of international donors implementing vertical programs, independent of the government, increased the complexity of the system by creating fragmentation in the system [53]. Similarly, Kimaro and Nhampossa looked at the problems associated with the unsustainable health information system in Tanzania and Mozambique.

One of the main problems identified was the fact that health information systems were built by different international donor projects. This was an issue as there was poor compatibility between the systems, making information exchange and system integration difficult. There was also a lack of capacity building whilst the donors were involved, which left the Ministry of Health $(\mathrm{MoH})$ unable to maintain and accommodate any changes that had taken place, eventually leading to a failure in the health information system [54]. 


\section{Lessons for Somalia}

- There is a need for equitable infrastructure in order to implement a nationwide health information system

- Health information needs to be centralised and run under a homogenous system, avoiding different donor run systems that are incompatible.

\section{Health financing strategies}

Newbrander et al looked at financing mechanisms in South Sudan. South Sudan employed a Multi-donor Trust Fund, which funnelled US\$252 million for development. The ministry of health were then given the chance to use this money to contract out to agencies to address specific health priorities. The challenges that they faced were the lack of financial and human resources management capacity and transparency to achieve these goals, leading to the failure of this strategy [36].

Witter also looked at health financing in post conflict and fragile states. She found that most studies had looked specifically at the role of donors, citing the influence and funding that the donors offer during the post conflict period. She identified developing government capacity and stewardship as increasingly important as states transition out of the post conflict era. Witter commented on a lack of literature about the impact of post conflict financial strategies on the long term health sector development [55]. Lee et al alluded to this, highlighting that in these situations, states become reliant on donor funding to sustain their health systems. They dissected the total health expenditure (THE) in post war Liberia, finding that donor funding accounted for $47 \%$ of THE. The problems arose when the non-governmental organisations (NGOs) left the country causing a funding gap [48].

\section{Lessons for Somalia}

- Donor funds could be pooled to provide a sum of money that can be delegated by the Ministry of Health in order to meet national health objectives.

- There is a need for adequate human resources, financing and transparency for the above goals to be successfully reached.

- Sustainable funding sources need to be developed, so that the funding gap is bridged when the donors either leave the country or curtail their assistance.

\section{Developing leadership and governance}

Cometto et al looked at the role of governance in the health sector recovery of South Sudan. They found that if the state had no legitimate authoritative government or stewardship, it would lead to the health sector being run by multiple stakeholders. This requires effective coordination or it will lead to a side-lining of government objectives resulting in the proliferation of various initiatives with no long-term goal [8].

In order to counter this, the South Sudanese government set up a coordination mechanism called the 'Health and Nutrition Consultative Group, which held meetings on a monthly basis hosting principal stakeholders, working together to achieve health sector recovery [8].

In 2005, ineffective management, poor delegation of responsibilities and poor dissemination of procedures plagued the south Sudanese Ministry of Health. This led to capacity building effort by development partners focusing on provision of training and equipment, but these failed to prosper due to systemic inadequacy. It was then suggested that in a situation of systemic inadequacy core managerial functions should be prioritised as they provide the framework for provision programmes to be effectively delivered.

Bertone et al commented that early development of a central policy framework was important to counter the fragmentation and verticalisation of the health sector during the immediate post-conflict phase [56].

Another study by Haar et al echoed these findings, commenting on the importance of government stewardship in order to establish good evaluation, supervision and regulation of the health system, so that strategies were evidence based and efficient. They also reiterated the importance of building capacity early on in the recovery process by handing over responsibility of delegation to local partners and ministries of health [9].

\section{Lessons for Somalia}

- The government needs to put coordination mechanisms in place early on in the recovery phase to prevent fragmentation and verticalisation of the health system.

- At the early stage of capacity building, focus should be on contextual, systems, organisational and individual level factors as well as provision of the necessary operational tools to enable the development and enhancement of essential leadership competencies.

- Governance must take responsibility over supervision, evaluation and regulation of health system.

\section{Ensuring equitable access to medical prod- ucts, vaccines and technologies (MVT)}

There is very little literature available regarding medicines, vaccines and technologies in the context of rebuilding health systems in the post conflict environment. The only study available by Huff-Rousselle looked at establishing a pharmaceutical and medical supplies system in post conflict East Timor. They found that during the immediate post conflict phase there was often funding beyond the absorptive capacity of the medical supplies system, leading to pressure to spend money on pilot projects and experimental initiatives that were often unsustainable. It was recommended that the strategies for development of the medical supplies system in the post conflict context should be straight forward and 
uncomplicated due to human resource constraints and infancy of the organisations [57].

East Timor developed an operational essential drugs list (EDL). They had a central facility for storage of drugs and a functional distribution system. The next step will be the transition of ownership of the EDL, treatment and policy guidelines to the local institutions Securing sustainable funds for future supply is one of the major factors left to address.

\section{Lessons for Somalia}

- In the post conflict phase, it is important not to over complicate a system, but to keep strategies simple.

- Health systems require central well stocked drug stores, with good reliable distribution system

- The ownership of EDL, guidelines for treatment and policy guidelines needs to be handed over to local institutions.

\section{Conclusions}

The impact of conflict on the health status of the population as well as the health system can be catastrophic and be felt for years after the State has entered the post-conflict phase, but also provides an opportunity for reforms of the affected State's health sector. Those seeking to rebuild these health systems will face multiple challenges including the damaged health infrastructure and supply systems; the lack of health workers; fragmentation and lack of co-ordination between multiple formal and informal providers; and weak governance capacity to coordinate and develop the health system anew. There will also be opportunities to put in place elements that previously did not exist.

When assessing the needs of the health sector, it is important to look at historical impacts of previous policies on the equity of health services and try to address these with the new strategies, in order to strengthen the foundations of the new health system. An analysis of the strategies for rehabilitating the health system using the World Health Organization's health system building blocks was chosen. The following conclusions were made from the above analysis:

- When building new infrastructure and training systems it is important to do a thorough situation analysis in all states, regions and districts of the country, so that existing assets, whether they are health facilities, human resources, or members of the community and other resources that can contribute to health are identified. The analysis should also include health needs and local priorities. These will form the basis to develop both short, medium and long term staregic plan for rebuilding and rehabilitation of the health system in the country. This is also important, as the new infrastructure needs to meet the needs of its intended population in an optimum manner.

- The impact and contribution of local business community is vital in the post conflict Somalia, but their contribution could scanty, occasional and fragmented. To avoid this, coordination mechanisms supervised by a joint body consisting of the government, business community and local community should be put in place in order to ensure they are all pulling in the same direction and towards the national health objectives. This not only ensures that there is no unregulated proliferation of health services but also builds managerial capacity amongst the local community and public sector institutions.

- Inequity that exists in the health service and infrastructure as the result of long conflict and underinvestment need to be addressed as a matter of urgency. Somalia's needs to develop tailor made implementation strategies such as homogenous health information and viable and functioning drug distribution systems in addition to nfrastructural development that will respond to the health needs of the population across the country.

- Human resources development efforts need to consider issues such as the legal and regulatory framework, coordination and monitoring. This calls for clear definition of roles and functions between the federal and state governments. While the federal government's primary responsibility should be in terms of policy and planning, financing and legal, the state governments would retain the functions of human resources management, including production, deployment and retention.

- Capacity and ownership need to be encouraged from an early stage in order to ensure a smoother transition when external support either ceases or diminishes. This requires a strengthening of the professional relationship between development partners and their local counterparts to enable skills transfer and reduce donor dependency.

- When expanding health services or developing new initiatives will require strong partnership between the public and private sector. The role of the later has expanded during the period of conflict. Simple, practical and straightforward join plans which are relevant and effective to address country's health needs are a better option, as they are less donor dependant, more financially sustainable and it will be easier to transition control once development partners leave the country or their support is diminshed.

- The potentials of Somali diaspora contributions to the health system and health care development in Somalia are promising. Short-term contributions in terms of funding certain health services were observed as the best option for the current country situation.

- Creation of a coordinating body from within the healthcare sector in Somalia to advocate the positive role of the Somali diaspora, including 
medical diaspora in the development of the healthcare system, to document the knowledge and skill gaps that are needed to be filled in the health care development in Somalia, to liaise with the diaspora, and to effectively coordinate their contributions is the proposed mechanism through which to improve diaspora contributions to improve health system in the country.

\section{Summary in Somali}

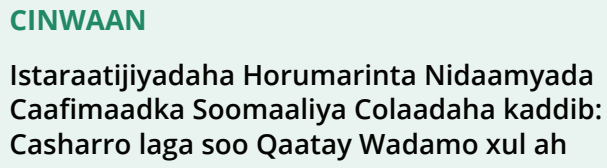

\section{SOOKOOBID}

Ilaa bilowgii 1991, Soomaaliya waxay lahayd nidaam daryeel caafimaad oo macquul ah, lehna tiro wanaagsan ee cusbitaalo agabkoodu $u$ dhan yahay kuna kala yaalay Muqdisho iyo Hargeysa, sidoo kale waxaa gobollada iyo degmooyinku lahaayeen cusbitaalo, rugo caafimaad, xaruumo bukaan socodyo iyo xarumo caafimaad ee hooyada iyo dhallaanka(MCH). Si kastaba ha ahaatee, iskahorimaadkii ka dhashay dagaalladii sokeeye,wuxuu sababay in ay baaba'aan nidaamkii daryeelka caafimaadka bulshada ee ka jiray dalka.

Soomaaliya kali kuma aysan aheyn isku-dhacyada. Tirada guud ee isku dhacyada adduunka ka dhacay sanadkii 2019 waxay ahaayeen 54, qaar badan oo ka mid ahi hadda waxay galeen waji-colaado-kaddib (post-conflict), halkaas oo dagaal fool-ka-fool ahi (furan) uu ka-dhammaaday. Waxaa jira caddeymo isa soo taraya oo sheegaya in khilaafku uu saameyn ba'an ku yeesho nidaamyada caafimaadka iyo xaaladda caafimaad ee dadka.

Soomaaliya gudaheeda, marxaladdii colaadeed kaddib waxay haysataa fursad gaar ah, oo abuuraysa rajada ah, in dib loo bilaabo horumarinta iyo dib-uhabaynta hawlaha caafimaadka. Xilligan la joogo, nidaamyada caafimaadka ee Soomaaliya waxay wajahayaan culeys ay ugu wacan tahay nidaamkii caafimaad ee jiray oo burbur ku yimid, u-sinnaan la'aanta dhinaca daryeelka la bixinayo, iyo saameynta muddada dheer ee iska-horimaadku ku yeeshay culays xoog leh nidaamka caafimaadka.

Qoraalkan-dib-u-eegistu wuxuu falanqeynayaa qaab-dhismeedka dhaqan-celinta (baxnaaninta) nidaamyada caafimaadka ee waddammada colaadaha ka soo kabanaya. Aqoonta noocan ahi waxaa lagu dabakhi karaa baxnaaninta (dhaqancelinta) iyo horumarinta nidaamyada caafimaadka ee Soomaaliya, iyadoo la raacayo nidaamyada dhismaha caafimaadka ee Hay'adda Caafimaadka Adduunka (WHO).

Saameynta ay colaaduhu/iska-horimaadyadu ku yeeshaan caafimaadka guud ee bulshada, iyo sidoo kale nidaamyada iyo qaab dhismeedka caafimaadka, waxey noqon kartaa musiibo aan laga soo kaban karin, taasoo la dareemo sanooyin kadib marka dalku galo xiliga ama wajiga kabashada oo ay joogsadaan iska-horimaadyadu, hase yeeshee waxey sidoo kale fursad siineysaa in dib-u-habeyn lagu sameeyo qeybaha caafimaad ee dalka ee waxyeeladu soo gaartay.
Acknowledgments

Not applicable

\section{Author contributions}

Sole author

\section{Disclosure statement}

The author has no competing interests.

Ethics and consent

Not applicable

\section{Funding information \\ Not applicable}

\section{Paper context}

This paper considers the devastating effects of conflicts on Somalia's overall health system. A framework for rehabilitation of health systems in other post-conflict settings was applied to draw lessons for Somalia using WHO's six health systems building blocks. There is a need to use a historical perspective for the analysis of the impact of previous policies on the equity of health services before establishing new strategies for a robust, appropriate and sustainable health system in Somalia.

\section{ORCID}

Maye Omar (iD https://orcid.org/0000-0002-34592011

\section{References}

[1] Qayad MG. Health care services in transitional Somalia: challenges and recommendations. Bildhaan: an International Journal of Somali Studies. 2008;7:10.

[2] Buschkens WF. Community health in the developing world: the case of Somalia. Van Gorcum; 1990.

[3] World Health Organization. Somalia: Health profile 2007 [cited 202028 July]. Available from: https:// www.who.int/gho/countries/som.pdf

[4] Gleditsch NP, Wallensteen P, Eriksson M, Sollenberg M, Strand H. Armed conflict 1946-2001: A new dataset. Journal of peace research 2002;39:615-637.

[5] Palik J, Siri Aas R, Methi F. Conflict Trends: A global overview 1946-2019. Oslo: PRIO; 2020 [cited 2021 $10 \mathrm{March}$. Available from: https://reliefweb.int/report/ world/conflict-trends-global-overview-1946-2019

[6] Atallah DG, Djalali A, Fredricks K, Arlington L, Bussio M, Nelson BD. Developing equitable primary health care in conflict-affected settings: expert perspectives from the Frontlines. Qualitative Health Research 2018;28:98-111.

[7] Junne G, Verkoren W. Postconflict development: Meeting new challenges. Boulder Co: Lynne Rienner Publishers; 2005.

[8] Cometto G, Fritsche G, Sondorp E. Health sector recovery in early post-conflict environments: experience from southern Sudan. Disasters 2010;34:885-909.

[9] Haar RJ, Rubenstein LS. Health in postconflict and fragile states. Washington. USA: US Institute of Peace; 2012. Available from: https://www.usip.org/ sites/default/files/SR 301.pdf.

[10] Macrae J ZA, Gilson L. . A triple burden for health 
sector reform: "Post"-conflict rehabilitation in Uganda. Social Science \& Medicine 1996;42:1095-1108.

[11] Percival V, Richards E, MacLean T, Theobald S. Health systems and gender in post-conflict contexts: building back better? Conflict and Health 2014;8:19.

[12] Sacks E, Morrow M, Story WT, Shelley KD, Shanklin D, Rahimtoola M, et al. Beyond the building blocks: integrating community roles into health systems frameworks to achieve health for all. BMJ Global Health 2019;3 Suppl 3: e001384.

[13] Geugjes M, Franziska, L., Stüber, V. Conflict Barometer 2018. Heidelberg, Germany: Heidelberg Institute for International Conflict Research (HIIK) e.V.; 2019. Available from: https://iugm.es/wp-content/ uploads/2019/03/Conflict-Barometer-2018.pdf.

[14] Watts CH, Foss AM, Hossain M, Zimmerman C, von Simson R, Klot J. Sexual violence and conflict in Africa: prevalence and potential impact on HIV incidence. Sexually Transmitted Infections 2010;86 Suppl 3:iii93-99.

[15] Klot JF, Auerbach JD, Berry MR. Sexual violence and HIV transmission: summary proceedings of a scientific research planning meeting. American Journal of Reproductive Immunology 2013;69:5-19.

[16] Bukuluki P, Kisuule JD, Makerere AB, Schei B, Sundby J. Perceptions of the drivers of sexual and gender based violence in post conflict Northern Uganda. International Letters of Social and Humanistic Sciences 2013;10:84-102.

[17] Briggs CM, Walji M, Anderson L. Environmental health risks and vulnerability in post-conflict regions. Medicine Conflict and Survival 2009;25:122-133.

[18] Kinyoki DK, Moloney GM, Uthman OA, Kandala N-B, Odundo EO, Noor AM, et al. Conflict in Somalia: impact on child undernutrition. BMJ Global Health 2017;2:e000262.

[19] Ghobarah HA, Huth P, Russett B. The post-war public health effects of civil conflict. Soc Sci Med 2004;59:869-884.

[20] Burkle Jr FM. The politics of global public health in fragile states and ungoverned territories. PLoS Currents 2017;9 ecurrents.dis. ba3beede71ca0746a0972aa3837ed618.

[21] Gleditsch KS, Beardsley K, Polo SMT. Issues in Data Collection: International Conflict. Oxford: Oxford University Press; 2017.

[22] Isaac I, Malaeb M, Bou khalil A, Musharrafieh U, AR B. Infectious diseases in times of conflict and war: the loyal companions J Infect Dis Epidemiol 2020;6: 172.

[23] McDonald G. Mental health consequences of long term conflict. BMJ 2007;334: 1121-1122.

[24] Gobat J, Kostial MK. Syria's conflict economy: International Monetary Fund; 2016. Available from: https://www.imf.org/external/pubs/ft/wp/2016/wp16123. pdf.

[25] Jaafar HH, Zurayk R, King C, Ahmad F, Al-Outa R. Impact of the Syrian conflict on irrigated agriculture in the Orontes Basin. International Journal of Water Resources Development 2015;31:436-449.

[26] Adelaja A, George J. Effects of conflict on agriculture: evidence from the Boko Haram insurgency. World Development 2019;117:184-195.

[27] Omar A. Understanding and preventing attacks on health facilities during armed conflict in Syria. Risk
Management and Healthcare Policy 2020;13:191.

[28] Briody C, Rubenstein L, Roberts L, Penney E, Keenan W, Horbar J. Review of attacks on health care facilities in six conflicts of the past three decades. Conflict and Health 2018;12:19.

[29] Bou-Karroum L, El-Harakeh A, Kassamany I, Ismail H, El Arnaout N, Charide R, et al. Health care workers in conflict and post-conflict settings: systematic mapping of the evidence. PloS One 2020;15:e0233757.

[30] Terry F. Violence against health care: insights from Afghanistan, Somalia, and the Democratic Republic of the Congo. Int'l Rev Red Cross 2013;95:23.

[31] Barr A, Garrett L, Marten R, Kadandale S. Health sector fragmentation: three examples from Sierra Leone. Global Health. 2019;15:1-8.

[32] Mohamed Ibrahim MI, Alshakka M, Al-abd N, Bahattab A, Badulla W. Availability of essential medicines in a Country in conflict: a quantitative insight from Yemen. Int J Environ Res Public Health 2021;18:175.

[33] World Health Organization. Development of the roadmap on access to medicines and vaccines 20192023. 2019 [cited $202111 \mathrm{March}$ ]. Available from: https://www.who.int/medicines/access use/road-mapmedicines-vaccines/en/

[34] Zwi A, Ugalde A. Towards an epidemiology of political violence in the third world. Social Science \& Medicine 1989;28:633-642.

[35] Rubenstein LS. Post-conflict health reconstruction: search for a policy. Disasters 2011;35:680-700.

[36] Newbrander W, Waldman R, Shepherd-Banigan M. Rebuilding and strengthening health systems and providing basic health services in fragile states. Disasters 2011;35:639-660.

[37] Omar M. Strengthening District health management in low-middle income countries: Reflections and way forward [Commentary]. Jurnal Administrasi Kesehatan Indonesia 2020;8:123-140.

[38] Dyer O. New report on corruption in health. Bulletin of the World Health Organization 2006;84:84-85.

[39] Siverson RM, Johnson RA. Politics and parasites: the contribution of corruption to human misery. International Studies Quarterly 2014;58:199-206.

[40] Vian T. Anti-corruption, transparency and accountability in health: concepts, frameworks, and approaches. Glob Health Action 2020;13 Suppl 1:1694744.

[41] Ensor T, Duran-Moreno A. Corruption as a challenge to effective regulation in the health sector. In: Richard B. Saltman, and RB, Mossialos E, editors. Regulating entrepreneurial behaviour in European health care systems. Geneva: World Health Organization; 2002. p. 106.

[42] Collier P, Hoeffler A. Greed and grievance in civil war. Oxford Economic Papers 2004;56:563-595.

[43] World Health Organization, UK-AID. Integrating a focus on anti-corruption, transparency and accountability in health systems assessments Geneva, Switzerland: World Health Organization; 2018 [cited 202013 December]. Available from: https://apps.who.int/iris/bitstream/hand le/10665/310991/9789241515177-eng.pdf

[44] Gaber S, Patel P. Tracing health system challenges in post-conflict Côte d'Ivoire from 1893 to 2013. Global Public Health 2013;8:698-712.

[45] Kumar K. Rebuilding societies after civil war: Critical roles for international assistance. London: Lynne Rienner 
Publishers; 1997.

[46] Macrae J. Dilemmas of legitimacy, sustainability, and coherence: rehabilitating the health sector. Rebuilding societies after civil war: critical roles for international assistance. London: Lynne Rienner Publishers; 1997.

[47] Le Sage A, Majid N. The livelihoods gap: responding to the economic dynamics of vulnerability in Somalia. Disasters 2002;26:10-27.

[48] Lee PT, Kruse GR, Chan BT, Massaquoi MB, Panjabi RR, Dahn BT et al. An analysis of Liberia's 2007 national health policy: lessons for health systems strengthening and chronic disease care in poor, postconflict countries. Global Health 2011;7:1-14.

[49] Abdalla FM, Omar MA, Badr EE. Contribution of Sudanese medical diaspora to the healthcare delivery system in Sudan: exploring options and barriers. Human Resources for Health 2016;14 Suppl 1:28.

[50] Huicho L, Dieleman M, Campbell J, Codjia L, Balabanova D, Dussault $\mathrm{G}$ et al. Increasing access to health workers in underserved areas: a conceptual framework for measuring results. Bulletin World Health Organization. 2010;88:357-363.

[51] Snell B, Martins N, Malau C, Belo OMF, Gomes L, Vital $\mathrm{M}$ et al. Strengthening health systems in Timor-Leste. Develop Bull 2005;68:95-98.

[52] Fujita N, Zwi AB, Nagai M, Akashi H. A comprehensive framework for human resources for health system development in fragile and post-conflict states. PLoS Med 2011;8:e1001146.

[53] Mutale W, Chintu N, Amoroso C, Awoonor-Williams K, Phillips J, Baynes $\mathrm{C}$ et al. Improving health information systems for decision making across five sub-Saharan African countries: implementation strategies from the African Health Initiative. BMC Health Serv Res 2013;13 Suppl S2:S9.

[54] Kimaro HC, Nhampossa JL. Analyzing the problem of unsustainable health information systems in lessdeveloped economies: case studies from Tanzania and Mozambique. Information technology for development. 2005;11:273-298.

[55] Witter S. Health financing in fragile and post-conflict states: What do we know and what are the gaps? Social Science \& Medicine 2012;75:2370-2377.

[56] Bertone MP, Samai M, Edem-Hotah J, Witter S. A window of opportunity for reform in post-conflict settings? The case of human resources for health policies in Sierra Leone, 2002-2012. Conflict and Health 2014;8:11.

[57] Huff-Rousselle M. The logical underpinnings and benefits of pooled pharmaceutical procurement: a pragmatic role for our public institutions? Social Science \& Medicine 2012;75:1572-1580. 